\title{
Interações fictivas enquanto estratégia comunicativa em sujeitos com agramatismo: um estudo de caso
}

\author{
Lou-Ann Kleppa \\ Universidade Federal de Rondônia (UNIR), Porto Velho, Rondônia, Brasil \\ kleppa@unir.br
}

DOI: http//dx.doi.org/10.21165/el.v45i2.674

\begin{abstract}
Resumo: Este estudo se insere na Neurolinguística discursivo-enunciativa e pretende apresentar o potencial comunicativo de interações fictivas em estruturas sintaticamente reduzidas, produzidas por dois sujeitos afásicos com agramatismo. Os dados apresentados são estruturados em forma de tópico-comentário e são não-finitos. O conceito de interação fictiva (fictive interaction) foi elaborado por Pascual em 2002 e desde então a autora e colegas vêm trabalhando com o fenômeno no sentido em que são trazidas vozes ao discurso que não correspondem necessariamente a discursos diretos reportados. Nos dados examinados aqui, interações fictivas apresentam um formato peculiar: na fala de OJ, percebe-se predominância de pares de pergunta e resposta, já na fala de MS há maior recorrência de discursos diretos enquadrados numa encenação que demonstra o seu querer-dizer.
\end{abstract}

Palavras-chave: interações fictivas; agramatismo; fala reduzida; tópico-comentário; nãofinitude.

Fictive Interactions as a Communicative Strategy in Speakers with Agrammatis m: a Case Study

\begin{abstract}
This study is grounded in Enunciative-Discursive Neurolinguistics and intends to present the communicative potential of fictive interactions in syntactically reduced structures produced by two aphasic individuals with agrammatism. The data presented here are syntactically structured in the form of a topic-comment sentence and are non-finite. Pascual elaborated the concept of fictive interaction in 2002; since then, the author and colleagues have been working on the phenomenon in the sense that voices are brought into discourse and do not necessarily correspond to direct reported speech. In the data examined here, fictive interactions have a peculiar format: in OJ's speech, a predominance of question and answer pairs can be observed, while in MS' speech there is a greater recurrence of direct discourse framed in a scenario that demonstrates what he wishes to say.
\end{abstract}

Keywords: fictive interactions; agrammatism; reduced speech; topic-comment structure; nonfiniteness.

\section{Interações fictivas}

Estudos sobre fictividade desenvolvidos na Linguística Cognitiva (TALMY, 2000 apud PASCUAL 2006b; LANGACKER 1991, 1999 apud PASCUAL 2006b) apontam que certas expressões linguísticas são apenas indiretamente relacionadas a seus referentes e que uma cena não real é comumente apresentada por falantes como um meio de acessar mentalmente a cena real. Já o conceito de interação fictiva (fictive interaction) foi elaborado por Pascual em 2002 e, desde então, a autora e colegas vêm 
trabalhando com o fenômeno (que se opõe à interação factiva) no sentido em que são trazidas vozes ao discurso que não necessariamente correspondem a discursos diretos reportados ipsis literis. Não se trata de discurso fictício ou imaginário, já que não é concebido como ocorrendo no universo da fantasia ou num cenário hipoteticamente contrafactual, mas se trata de encaixar uma troca verbal conceitual no âmbito do monólogo (PASCUAL, 2006a).

Pascual (2006a, 2006b, 2014a, b) aponta para a abundância de interações fictivas nas línguas naturais e para a variedade de contextos sintáticos em que emergem. Em 2014, Pascual lançou um livro sobre interações fictivas e para 2015 Pascual e Sandler estão organizando um livro em que vários autores analisam interações fictivas: (i) sob diferentes aspectos: por exemplo, o fonológico (Dornelas, Rocha e Arantes); o semântico (Sandler); com relação ao gesto (Abrantes); (ii) em contextos discursivos específicos: no jornalismo (Fonseca); (iii) em diversas línguas (Oakley e FitzGerald), inclusive língua de sinais (Jarque); e (iv) em diferentes contextos sócio-cognitivos: no autismo (Dornelas e Pascual); na afasia (Versluis e Kleppa).

Segundo Pascual (2006b, p. 249), interações fictivas estruturam a linguagem, cognição e discurso:

[...] my main theoretical assumption is that one of the basic underlying structures of cognition, discourse and language derives from our life-long experience as social beings constantly exposed to and engaged in situated communicative exchanges with fellow speakers. Hence, the basic hypothesis underlying the notion of fictive interaction is that speech, linguistic meaning, and language in general are fundamentally interactional in nature (cf. Bakhtin 1973, 1975; Voloshinov [1929] 1986; Vygotsky 1962, 1978)

Do ponto de vista pragmático, interações fictivas se apresentam como uma troca comunicacional não genuína, no sentido em que não devem ser interpretados, na situação de produção, como referentes a ela (assim como o discurso direto). Interações fictivas envolvem demonstrações/atuações em vez de descrever um referente. É comum que envolvam a mistura de diferentes vozes (e pontos de vista) e parecem ser motivados pela inefabilidade da descrição de seu referente (PASCUAL, 2006b, p. 260).

Nos dados de afasia de MS e OJ analisados aqui, encontramos dois padrões de interações fictivas: jogo de perguntas e respostas e discurso direto que demonstra um querer-dizer. Como veremos a seguir, ambos foram estudados por Pascual.

Esther Pascual iniciou seus estudos sobre interações ficitivas no contexto jurídico, analisando a argumentação final de um promotor de um caso de homicídio, em que as interações fictivas emergiam sob a forma de jogos de pergunta e resposta que o promotor fazia diante da defesa e do júri. Neste triálogo, o promotor assume em seu monólogo as vozes da defesa e do júri, formulando perguntas que ele mesmo, no papel de promotor, responde. Deste modo, o promotor antecipa, formula e responde questões dos seus ouvintes (PASCUAL, 2006a).

Em palestra proferida por Pascual em 2014, a autora cita Bánréti (2010) que elaborou uma série de experimentos com sujeitos afásicos húngaros e sujeitos controle para testar a recursividade da língua. Em um experimento, é mostrada ao sujeito uma fotografia de uma mulher na balança. A imagem vem acompanhada da seguinte pergunta: “O que ela estaria pensando?" Os resultados de Bánréti mostram que a maioria dos sujeitos controle respondeu fazendo uso do discurso indireto ou descrições: "que está pesada", "no seu peso", ao passo que todos os sujeitos afásicos assumiram o 
ponto de vista da pessoa na fotografia e emitiram como resposta discursos diretos: "sério? Tão pesada?". Em outras palavras, todos os sujeitos afásicos testados demonstraram, ao invés de descrever, o que a moça da fotografia estaria pensando. A conclusão de Pascual (2014b) é que interações fictivas funcionam como estratégia de adaptação no caso de afasias.

Seguindo a intuição de que a demonstração, através do discurso direto, era uma forma conceitualmente mais direta e popular que a descrição, o experimento relatado acima foi replicado, em 2015, pela autora do presente texto em sala de aula, numa turma de Letras (3. semestre) na Universidade Federal de Rondônia (UNIR) - com uma variação. Além da fotografia do experimento original (ver figura 1), foi apresentado um cartum em que se observa uma mulher presa a um balão (como se flutuasse) conferindo seu peso na balança (ver figura 2). 27 alunos participaram do experimento, sendo que 14 receberam a figura 1 e 13 alunos receberam a figura 2. Dos 14 alunos que receberam a figura 1, apenas um respondeu à pergunta "O que ela estaria pensando" com um discurso indireto: "Que está acima do peso". Os outros alunos que receberam a mesma figura responderam com discursos diretos.

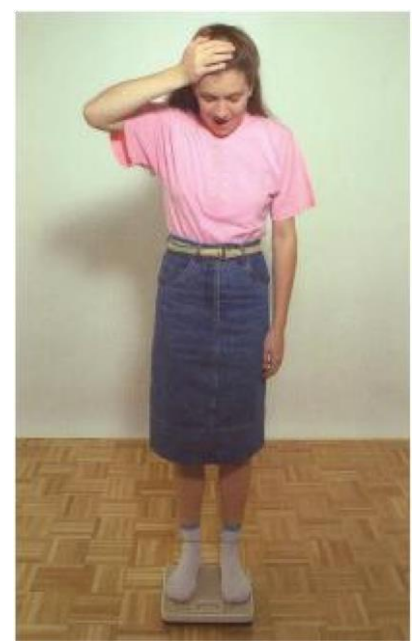

Figura 1. Fonte: Bánréti (apud Pascual, 2014b)

Exemplos de respostas à figura 1 são: "Nossa! Como estou gorda!", "Vou tirar os sapatos, eles é que são muito pesados", "Ah! Não gostei do meu peso!", 'Nossa, como eu emagreci!" Note-se que nenhum destes discursos diretos corresponde verbatim ao que a moça na foto de fato pensou ou disse.

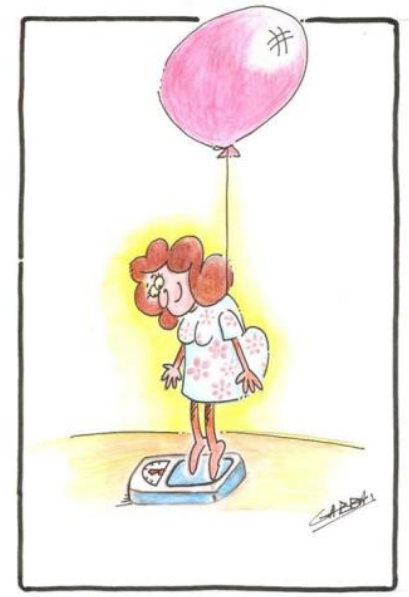

Figura 2. Cartum 
Dos 13 alunos que receberam a figura 2, seis elaboraram descrições ("Que estava magra ao ponto de parecer estar flutuando", "Que nesta posição ficará com menos peso", "Em ter peso de modelo") e sete alunos usaram discursos diretos ("Agora sim, estou magra!", "Estou me sentindo leve, de bem com a vida", "Agora estou menos pesada"). Os resultados desse experimento são apresentados na tabela 1.

Tabela 1. Resultados do experimento

\begin{tabular}{c|c|c}
\hline Sujeitos & cartum: 13 & foto: 14 \\
\hline Descrição & 6 & 1 \\
\hline $\begin{array}{c}\text { Interação } \\
\text { fictiva }\end{array}$ & 7 & 13 \\
\hline
\end{tabular}

A preferência, no geral e no caso específico da figura 1, dos alunos de Letras da UNIR por interações fictivas na forma de discursos diretos não indica que sejam afásicos, mas que recorrem a uma estratégia básica da interação face-a-face: o diálogo. Acreditamos que a diferença entre as figuras 1 e 2 seja que a fotografia tem um apelo maior, já que a identificação dos alunos com a pessoa representada na fotografia se faz de maneira mais direta que a identific ação com a personagem do cartum. Nesse sentido, é mais propício o uso de discurso direto aplicado a uma imagem com a qual o sujeito do experimento pode se identificar. Podemos concluir que interações fictivas estabelecem um canal metonímico com situações e eventos não-factuais - por isso conceituais.

Na fala afásica, mais especificamente na fala de sujeitos com agramatismo, encontramos interações fictivas - mas a estrutura sintática dessas construções apresenta características próprias. Como veremos nas seções seguintes, a fala agramática apresenta peculiaridades (fala elíptica num tempo maior de fala que o normal), que podem ser entendidas como estratégias adaptativas do sujeito à afasia.

\section{Fala reduzida e os sujeitos que a produzem}

Este estudo se insere na Neurolinguística discursivo-enunciativa tal como desenvolvida no Instituto de Estudos da Linguagem (IEL) da UNICAMP a partir das interações com sujeitos afásicos e não-afásicos no âmbito do Centro de Convivência de Afásicos (CCA) e cujas autoras mais expoentes são Coudry (1996), Morato (2002, 2010) e Novaes Pinto (1992, 2012). A abordagem adotada aqui diferencia-se dos modelos correntes de afasia num aspecto fundamental: não toma a linguagem do sujeito afásico como evidência de (in)competência linguística, nem como objeto de conhecimento. Nesse sentido, não especulamos sobre o material linguístico que falta, mas analisamos o que de fato foi dito pelos sujeitos com afasia.

Entendemos que para detectar as dificuldades linguísticas de sujeitos afásicos, é preciso privilegiar a análise de contextos de comunicação verbal em que estejam envolvidos. Há, nessa abordagem, uma aposta no sujeito ativo, responsivo (BAKHTIN, 1997) que se relaciona com a sua língua e seu distúrbio linguístico. Nesse sentido, acreditamos ser possível trazer a Teoria da Adaptação para a Neurolinguística de orientação enunciativo-discursiva: se compreendemos a afasia como uma questão social (além de linguística, cognitiva e de saúde), faz sentido que apostemos numa teoria que postula que a linguagem do sujeito afásico é como é devido à interação com o outro, uma adaptação ao tempo do diálogo. Entendemos que as duas abordagens não são completamente congruentes, mas há pontos de convergência possíveis, de modo 
que a Teoria da Adaptação pode iluminar processos específicos do agramatis mo. Pelo fato de a Teoria da Adaptação e seus adeptos trabalharem com a aplicação de testes padronizados, contabilizarem omissões e substituições de palavras na fala agramática e lidarem com elipses e 'fala telegráfica' de uma maneira meramente descritiva e pouco crítica, acreditamos que seja necessário explicitar os limites da adoção da Teoria da Adaptação neste trabalho. Adotamos a Teoria da Adaptação porque oferece uma visão do sujeito afásico enquanto sujeito ativo que adapta a sua fala à situação de fala, relaciona a fala agramática ao tempo de fala e prevê uma sintaxe que chamamos de fala reduzida (cf. KLEPPA, 2008, 2009, 2010, 2014).

A Teoria da Adaptação foi desenvolvida por Kolk e colegas desde 1985. Esta teoria não analisa a fala agramática como sintoma direto da lesão cerebral (ver HEESCHEN; KOLK, 1988; KOLK; HEESCHEN, 1990), mas como resultado de uma estratégia de adaptar a sua fala à situação comunicativa. O problema do distúrbio linguístico do sujeito com fala agramática foi formulado através da hipótese da janela temporal (Temporal Window Hypothesis). Os trabalhos de Haarmann e Kolk (1991) e Kolk (1995) focam no distúrbio temporal de processamento, que basicamente consiste numa limitação de capacidade para preencher simultaneamente os espaços sintáticos de uma oração. A capacidade de processar a língua a ser produzida é afetada de tal maneira que a informação ou é ativada tardiamente ou decai antes de ser encadeada com outras informações que possam fazer emergir uma fala inteligível para o interlocutor.

Para a Teoria da Adaptação, a fala agramática é o resultado de uma estratégia para evitar uma sobrecarga computacional, portanto estruturas simplificadas são planejadas. Sendo assim, o problema linguístico do sujeito afásico com agramatis mo não é a dissolução da linguagem, mas o tempo de processamento da linguagem. No âmbito da Teoria da Adaptação, o agramatismo é definido como "fala 'telegráfica/ elíptica' em tempo de fala maior que o normal.". Isso não significa que toda a fala de sujeitos com agramatismo seja reduzida. Há sentenças completas em meio a sentenças reduzidas.

Preferimos abandonar o termo 'fala telegráfica' e a metáfora do telegrama comumente usados para descrever a fala agramática, porque não acreditamos ser possível compará-los ponto a ponto. A economia de palavras é evidente nos telegramas, ao passo que na fala agramática, as repetições, reformulações, construções desviantes e tentativas de formular sentenças completas não podem ser caracterizadas como economia. Além disso, os telegramas são escritos, não orais (o que envolve a pontuação nos telegramas e, na fala agramática, envolve pausas, curvas entonacionais, qualidade de voz e gestos faciais e corporais). O tempo de produção dos telegramas (e a pressão para executar a tarefa) é diferente do tempo (e da pressão) para falar com um interlocutor face-a-face, portanto mecanismos diferentes de produção entram em jogo. Os objetivos comunicacionais dos telegramas (pedidos, avisos) são completamente diferentes daqueles envolvidos em conversas espontâneas.

Sintaticamente, foi observado em Kleppa (2008) que tanto telegramas (realizados em experimento) como a fala agramática de MS e OJ são caracterizados pela não-finitude (ou não há verbos na sentença/enunciado, ou os verbos se apresentam em suas formas nominais). Contudo, foi notada uma tendência maior para a ausência de verbos na fala dos sujeitos afásicos e uma tendência maior para o uso de verbos não conjugados nos telegramas. Por fim, foi observado que a ordem das palavras diferenciava telegramas de fala agramática: enquanto os telegramas apresentavam as palavras na ordem canônica (SVO + adjuntos), na fala de MS e OJ preponderava a 
ordem tópico-comentário (cf. KLEPPA 2008, 2009, 2010), mais especificamente hanging topics (ver seção seguinte).

Os dados dos sujeitos identificados como MS e OJ foram coletados em situações de conversa espontânea e acredita-se que, nesse contexto interacional, os sujeitos adaptem sua fala à condição afásica e ao interlocutor, explorando o conhecimento compartilhado entre eles através de esquemas interativos. Tanto MS como OJ são do sexo masculino, destros, falantes nativos de português, sofreram AVC (MS tinha 60 anos quando entrevistado e estava afásico havia 4 anos; OJ tinha 55 anos, 13 após o acidente neurológico, sendo que durante os seis primeiros anos após o AVC, OJ relata ter ficado "mudo"), foram entrevistados e gravados em 2006 e assinaram o termo de consentimento livre e esclarecido.

\section{Estruturas de tópico-comentário}

A estrutura de tópico-comentário sentencial refere-se ao "empacotamento" de informação - ou a estrutura informacional - em oposição ao próprio conteúdo informacional. A literatura sobre este fenômeno é vasta, mas não unificada (cf. LI; THOMPSON, 1976; PONTES, 1987; JACOBS, 2001; BELFORD, 2006; MASLOVA; BERNINI, 2006). Em relação ao uso de construções de tópico por sujeitos afásicos, Webster et al. (2001) mostra evidências de que sujeitos com agramatismo fazem uso regular de padrões de tópico-comentário, contendo estruturas de comentário normais, porém pouco complexas. Em termos funcionais, o uso de estruturas de tópicocomentário por parte de sujeitos afásicos é considerado como uma escolha estratégica para manter os turnos do diálogo e para evitar a pressão temporal e a reformulação, consequentemente mantendo a preservação da face (BEEKE; WILKINSON; MAXIM, 2007, WILKINSON; BEEKE; MAXIM, 2003, WILKINSON, 2009).

A característica mais básica de estruturas de tópico-comentário é a separação tanto conceitual como formal - entre o tópico e o comentário. Há diversos níveis em que essa separação pode ser observada: fonologicamente, há uma pausa observável entre o tópico e o comentário; e a curva entonacional pode cair ou subir ao fim do tópico (nos dados, é sinalizada com setas). Sintaticamente, pode haver diferentes níveis de integração entre o tópico e o comentário. No caso de hanging topics, não há qualquer integração sintática entre o tópico e o comentário: o interlocutor precisa conectar o tópico com o comentário conceitualmente para interpretar o enunciado. Este tipo de construção é o mais abundante em nossos dados. De acordo com Gundel (1988, p. 224), hanging topic é a estrutura de tópico-comentário prototípica, já que representa a composição extrema de estruturas de tópico-comentário: separação estrutural máxima entre os dois elementos da estrutura.

As relações observadas entre tópico e comentário são de dois tipos: aboutness (anúncio do tema sobre o qual se vai dizer algo no comentário) ou frame-setting (estabelecimento de um cenário vinculado ao que se vai dizer no comentário). No primeiro caso, o falante elege um referente (uma pessoa, coisa, evento) e depois comenta sobre ele. No episódio a seguir ${ }^{1}$, em que MS pergunta à sua interlocutora onde mora seu namorado, observamos esta relação de aboutness:

\footnotetext{
${ }^{1}$ Nas transcrições, as setas $[\downarrow$ e $\uparrow]$ indicam a entonação, as reticências [...] indicam pausas, caixa alta [NADA] indica alto volume de voz e dois pontos [:] indica alongamento do som. Em itálico e entre parênteses estão descritas as ações dos interlocutores e em itálico está o fragmento para o qual se quer chamar atenção na presente análise.
} 
O segundo tipo de relação estabelecida pelo tópico é de frame-setting. Nesse caso, o tópico estabelece um cenário ou delimita um espaço/ tempo/ estado, como se pode observar no episódio a seguir:

(02) OJ estado de São Paulo $\uparrow$... NADA $\downarrow$ Nada, nada, nada. Derrame.

LK $\quad$ ah, não lembra das coisas do estado de São Paulo $\uparrow$

OJ $\quad \mathrm{i}::: \mathrm{h}$, isso (movimenta a mão esquerda repetidas vezes em direção a si mesmo)

antes, antes, antes $\uparrow$

LK $\mathrm{mh}, \mathrm{mh}$.

OJ m::.::udo.

No episódio (02) podemos observar dois tópicos do tipo frame-setting: o primeiro delimita o espaço ao qual OJ refere não ter mais memórias após o AVC (o estado de São Paulo); o segundo delimita o tempo ('muito tempo atrás', expressado pela repetição de 'antes') em que ele não conseguia falar. Note-se que nos episódios acima não há presença de verbos conjugados.

Acreditamos que o sujeito com agramatismo não adapta sua fala apenas às suas capacidades reduzidas de performar operações sintáticas simultâneas, mas também adapta a sua fala pragmaticamente ao interlocutor. Pretendemos apresentar o potencial comunicativo de interações fictivas em estruturas sintaticamente reduzidas produzidas por dois sujeitos com agramatismo.

\section{Interações fictivas na fala de MS e OJ}

$\mathrm{Na}$ fala dos dois sujeitos examinada aqui, interações fictivas são recorrentes, mas, por serem proferidas por sujeitos afásicos, apresentam uma estrutura de tópicocomentário. Nas interações fictivas de OJ, a pergunta do interlocutor é antecipada/ adivinhada/ ecoada e em seguida respondida. Os pares de pergunta e resposta estão marcados no episódio a seguir:

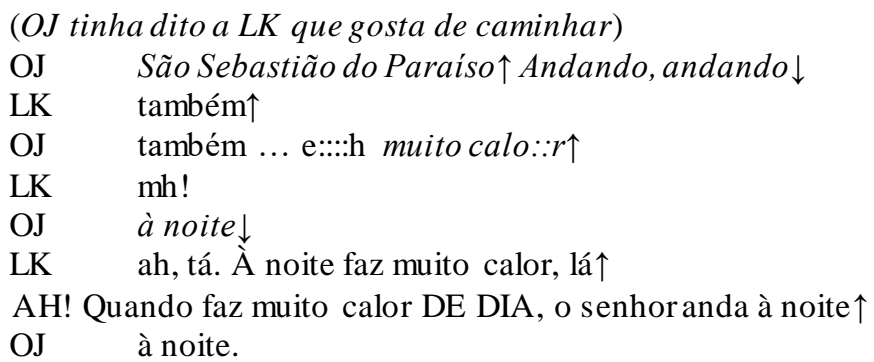

Na primeira linha, OJ apresenta o tópico (São Sebastião do Paraíso) que delimita o espaço em que desenvolve a atividade expressa no comentário (andando). Note-se que o verbo está no gerúndio, uma forma nominal. Na terceira linha, OJ anuncia o tópico (muito calor?) em forma de pergunta e responde com o comentário (à noite). De pronto, a interlocutora interpreta esta sequência de tópico-comentário como se o tópico fixasse um referente. Imediatamente ela refaz sua interpretação e percebe que a estrutura de hanging topic "muito calor? À noite" expressa uma relação condicional: quando faz muito calor de dia, então OJ caminha à noite. A pergunta expressa na terceira linha é retórica, e através dela OJ estrutura o pensamento e a linguagem. No episódio (03), OJ usou um diálogo fictivo (que não necessariamente se deu de fato) para expressar uma relação de condicionalidade. 
Neste outro episódio de OJ, temos novamente um par de pergunta e resposta em formato de tópico-comentário expressando uma interação fictiva. No episódio (04), a interlocutora havia perguntado quem faz a comida na casa dele e se ele ajuda na cozinha:

$$
\text { OJ almoçar } \uparrow \text { e aqui... toalha (faz o gesto de estender a toalha sobre a mesa) }
$$

A resposta de OJ novamente foi um diálogo fictivo dentro do seu monólogo. Ele usa o verbo no infinitivo (ou seja, não conjugado) para referenciar a ação de almoçar, como uma elipse de "Vamos almoçar? / Está na hora de almoçar?" Entendese que essa pergunta é adequada para o cenário em que a comida está pronta e OJ assume a tarefa de colocar a mesa. Através de fragmentos, OJ responde a pergunta da interlocutora ecoando uma pergunta prototípica de uma cena (pergunta que ele mesmo responde), demonstrando assim para a sua interlocutora que ajuda na cozinha, mas não prepara a comida. Nos dados de OJ, como se pode observar, a estratégia de criar pares de pergunta e resposta é recorrente. Exceto no episódio (02), os pares de pergunta e resposta são interações fictivas, ou seja, perguntas que não são dirigidas ao interlocuto $r$, mas retiradas de outros contextos interacionais e inseridas na própria fala.

Nas interações fictivas de MS, o interlocutor percebe claramente que uma cena é montada e situações dialógicas são encenadas para demonstrar uma resposta. No episódio (5), MS e a interlocutora conversavam sobre suas ex-esposas e como elas tinham entrado em sua vida. MS constrói a cena em que está retornando para o Brasil depois de morar muitos anos no Reino Unido, sentado ao lado de uma mulher que está chorando. Esta mulher seria a sua terceira esposa, e sua encenação demonstra como esta história começou:

(5) MS Isso.ahm éh ab iah ... di:.... pois, vindo para cá

LK Mh, hm.

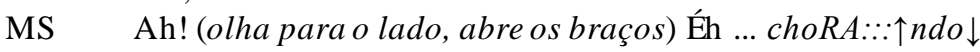

Através do tópico (frame setting) delimitador de espaço e tempo, MS anuncia que a cena a seguir se desenrola no caminho de volta para o Brasil, depois dos anos vividos no exterior. Ele dramatiza a cena, olha para o lado, como se alguém estivesse sentado ao seu lado, abre os braços, exclama em tom de lamentação e reproduz seu próprio discurso: "chorando?". Sua interlocutora compreende que MS conheceu a terceira esposa no avião.

No episódio (06), MS encena uma história para representar um conceito. Questionado se teve uma bicicleta na infância, refere a uma situação passada usando fala reduzida (desta vez, sem qualquer verbo) e um grande repertório de gestos faciais e corporais, acompanhados de prosódia sugestiva. Ao invés de responder positivamente ou negativamente se teve uma bicicleta na infância, ele responde apresentando uma cena que explica por que ele nunca teve uma bicicleta.

(06) MS (aponta para si mesmo) ah mamãe papai ... Éh

LK a:::::::::h

MS (olha para cima e dá tchauzinho para a direita e esquerda)

$\tilde{A}:: .: .:: h$ ! (aponta para o pulso) ãh... re::ló::gio $\downarrow$

LK a:::h

MS ah! Ãh... (estica o pescoço, olha para cima e, numa posição submissa, franze a testa)

éh bicicleta $\downarrow$

(endireita o corpo, balança a cabeça negativamente e assume um tom grave)

$N \tilde{A} O \downarrow$ Rólógio $\downarrow$ 
LK Nunca te deram uma bicicleta!

MS (levanta as palmas das mãos) éh, ...éh.

Em primeiro lugar, MS apresenta os personagens envolvidos: apontando para si mesmo, depois anunciando 'mamãe papai', ele sinaliza que está se referindo aos seus pais. Ao olhar para cima e acenar para os pais, MS dá a entender que eles são mais altos que ele. A distância estabelecida entre os pais e MS sugere que a cena se passou quando MS era uma criança. A seguir, ele aponta para o seu pulso e diz 'relógio', introduzindo assim um dos elementos em disputa entre a criança e os pais. Antes de expressar seu desejo por uma bicicleta (em tom choroso), sua postura corporal indica que ele implorou por uma bicicleta. Para assumir o papel dos pais, MS endireita o corpo, olha para baixo, balança a cabeça negativamente e assume um tom grave. Em alto e bom som, MS retoma (mas não literalmente) o discurso dos pais, encenando a resposta negativa que recebeu quando criança. Pode-se dizer que o discurso direto presente na interação fictiva metonimicamente desenha um cenário que o interlocutor reconhece e compreende. MS não descreveu, mas demonstrou, através de uma performance dramática, uma relação causal: não teve bicicleta na infância, porque seus pais decidiram que deveria ter um relógio.

\section{Considerações finais}

Os dados de sujeitos afásicos com agramatismo apresentados aqui mostram que os sujeitos afásicos lançam mão de esquemas interativos para representar eventos e situações passadas e relações gramaticais e conceituais. Ao teatralmente representar eventos passados, os sujeitos recorrem a tipos interativos - mais que tentar alcançar uma reprodução literal de um evento. Cada um à sua maneira, eles manipulam rotinas interativas para comprimir uma história numa sequência de turnos. Mais que isso, usam a estrutura interativa para propósitos não-referenciais, por exemplo: representar relações gramaticais (condicionalidade e causalidade) ou conceituais. MS e OJ usaram um repertório de estruturas elípticas que se baseia no conhecimento interativo compartilhado pelos interlocutores envolvidos no diálogo.

Os dados apresentados apontam para diferenças pessoais entre MS e OJ no tocante à construção de interações fictivas. Enquanto MS usa discursos diretos, encenando situações que conceitualmente veiculam o seu querer-dizer, OJ cria pares de pergunta e resposta em que a pergunta não é dirigida ao interlocutor, mas antecipa/ ecoa a fala de outro. Imaginamos que a relação que cada um tem com a língua e sua afasia possa explicar essas diferenças.

Antes do AVC, MS teve vários empregos intimamente ligados ao ofício da palavra: entre outros, foi repórter, guia turístico, professor e ator. Avalia que sua afasia melhorou depois de frequentar o CCA e esforça-se para interagir através da lingua ge m oral e escrita. Sempre muito expressivo, ele encena situações passadas para demonstrar seu querer-dizer.

OJ foi, antes do AVC, vendedor de peças de televisão. Como dito anteriormente, passou os seis primeiros anos após o AVC "mudo", respondendo pouco aos tratamentos fonoaudiológicos. Com postura reativa, não acredita que tenha problema de linguage $m$, mas de memória. Em geral, recorre frequentemente a pares de pergunta e resposta para demonstrar seu querer-dizer.

Por fim, acreditamos que a fala reduzida (com sua não-finitude e construções de tópico-comentário) seja uma adaptação do sujeito agramático à sua condição afásica, 
ao passo que as interações fictivas são uma adaptação pragmática ao interlocutor, com o qual compartilha esquemas interativos e conhecimento de mundo.

\section{REFERÊNCIAS}

BAKHTIN, M. O enunciado, a unidade da comunicação verbal. In: Estética da criação verbal. São Paulo: Martins Fontes, 1997. p. 289-327.

BÁNRÉTI, Z. Recursion in aphasia. Clinical Linguistics \& Phonetics, 24 (11), p. 906914, 2010.

BEEKE, S. R.; WILKINSON; R.; MAXIM, J. Grammar without sentence structure: A conversation analytic investigation of agrammatism. Aphasiology 21, (3/4), p. 256-282, 2007.

BELFORD, E. M. Topicalização de objetos e deslocamento de sujeitos na fala carioca: Um estudo sociolingüístico. 2006. 91 f. Dissertação (Mestrado em Letras) - Faculdade de Letras, Universidade Federal do Rio de Janeiro, Rio de Janeiro.

COUDRY, M. I. H. Diário de Narciso. Discurso e afasia: análise discursiva de interlocuções com afásicos. São Paulo: Martins Fontes, 1996. 205 p.

GUNDEL, J. K. Universals of topic-comment structure. In: HAMMOND M.; MORAVCZIK, E.; WIRTH, J. (org.). Studies in Syntactic Typology. Amsterdam: John Benjamins, 1988. p. 209-239.

HAARMANN, H. J.; KOLK, H. Syntactic priming in Broca's aphasics: evidence for slow activation. Aphasiology, 5, p. 247-263, 1991.

HEESCHEN, C.; KOLK, H. Agrammatism and paragrammatism. In: Aphasiology, 2, p. 299-302, 1988.

JACOBS, J. The dimensions of topic-comment. Linguistics, 39, p. 641-681, 2001.

KLEPPA, L. Estruturas de tópico-comentário na fala reduzida de um sujeito afásico. Estudos Linguísticos, 43 (2), p. 926-939, 2014.

. Estilo reduzido em sujeitos agramáticos, não-afásicos, telegramas e manchetes.RevistaL@elem (Dis)curso, 2, p. 93-108,2010.

. Fala reduzida em sujeitos afásicos e outros registros. Estudos Linguísticos, 38 (2), p. 249-258, 2009.

. Preposições ligadas a verbos na fala de uma criança em processo de aquisição de linguagem e de dois sujeitos agramáticos em processo de reconstrução de linguagem ou "Eu e você? Diferente. 2008. 163 f. Tese (Doutorado em Linguística) Instituto de Estudos da Linguagem, Universidade Estadual de Campinas, Campinas.

KOLK, H. A time-based approach to agrammatic production. Brain and Language, 50, p. 282-304, 1995.

KOLK, H.; HEESCHEN, C. Adaptation symptoms and impairment symptoms in Broca's aphasia. Aphasiology, 4, p. 221-232, 1990.

LI, C. N.; THOMPSON, S. A. Subject and topic: A new typology of language. In: LI, C. N. (org.). Subject and Topic. New York: Academic Press, Inc., 1976, p. 457-489. 
MASLOVA, E. A.; BERNINI, G. Sentence topics in the languages of Europe and beyond. In: Pragmatic Organization of Discourse in the Languages of Europe. Berlin, New York: Mouton de Gruyter, 2006. p. 67-120.

MORATO, E. M. (Org.). Sobre as afasias e os afásicos. Campinas: Editora da UNICAMP, 2002. 62 p.

. Introdução In: MORATO, E. M. (Org.). A semiologia das afasias: perspectivas linguísticas. São Paulo: Cortez, 2010. p. 9-21.

NOVAES PINTO, R. C. Agramatismo: uma contribuição para o estudo do processamento normal da linguagem. 1992. 173 f. Dissertação (Mestrado em Linguística) - Instituto de Estudos da Linguagem, Universidade Estadual de Campinas, Campinas.

Cérebro, linguagem e funcionamento cognitivo na perspectiva sócio-históricocultural: inferências a partir do estudo das afasias. Letras de Hoje, v.47 (1), p. 55-64, 2012.

PASCUAL, E. Questions in legal monologues: Fictive interaction as argumentative strategy in a murder trial. Text \& Talk, 26(3), p. 383-402, 2006a.

Fictive interaction within the sentence: A communicative type of fictivity in grammar. Cognitive Linguistics, 17(2), p. 245-267, 2006b.

Fictive Interaction: The Conversation Frame in Thought, Language, and Discourse. Amsterdam \& Philadelphia: John Benjamins, 2014a. 453 p.

The conversational mind: Fictive interaction in everyday, professional, and aphasic discourse. Palestra proferida no Departamento de Ciência Cognitiva, Hunan University, Changsha, China, 16 de maio de 2014b.

PASCUAL, E.; SANDLER, S. (org.). The Conversation Frame: Forms and Functions of Fictive Interaction. Amsterdam \& Philadelphia: John Benjamins (no prelo).

PONTES, E. O tópico no português do Brasil. Campinas: Editora Pontes, 1987. 169 p. WEBSTER, J.; FRANKLIN, S.; HOWARD, D. An Investigation of the Interaction between Thematic and Phrasal Structure in Nonfluent Agrammatic Subjetcs. Brain and Language, 78, p. 197-211, 2001.

WILKINSON, R. Projecting a reference in aphasic talk and normal talk. Discourse Processes, 46 (2-3), p. 206-225, 2009.

WILKINSON, R.; BEEKE, S.; MAXIM, J. Adapting to conversation: On the use of linguistic resources by speakers with fluent aphasia in the construction of turns at talk. In: GOODWIN, C. (Ed.). Conversation and brain damage. New York: Oxford University Press, p. 59-89, 2003.

Recebido em: 30/09/2015

Aprovado em: 04/03/2016 